Varieties of pre-reflective self-awareness: foreground and background bodily feelings in emotion experience

TO APPEAR IN INQUIRY: AN INTERDISCIPLINARY JOURNAL OF PHILOSOPHY

Giovanna Colombetti

Sociology \& Philosophy Department

University of Exeter

Amory, Rennes Drive

Exeter EX4 4RJ

UK 


\title{
Varieties of pre-reflective self-awareness: foreground and background bodily feelings in emotion experience
}

\begin{abstract}
How do we feel our body in emotion experience? In this paper I initially distinguish between foreground and background bodily feelings, and characterize them in some detail. Then I compare this distinction with the one between reflective and pre-reflective bodily self-awareness one finds in some recent philosophical phenomenological works, and conclude that both foreground and background bodily feelings can be understood as pre-reflective modes of bodily self-awareness that nevertheless differ in degree of selfpresentation or self-intimation. Finally, I use the distinction between foreground and background bodily feelings to characterize the experience of being absorbed in an activity, as opposed to accounts that imply that absorption involves bodily inconspicuousness.
\end{abstract}




\section{Varieties of pre-reflective self-awareness: foreground and background bodily feelings in emotion experience}

\section{Introduction}

What is it like to feel an emotion? As is well known, William James (1890) could not imagine experiencing an emotion without experiencing bodily feelings as well. $\mathrm{He}$ actually identified emotion with "our feeling of the [bodily] changes as they occur" (James 1890, p. 449). In a similar vein, Carl Lange (1885, p. 66) wrote: “[t]ake away the bodily symptoms from a frightened individual [...]; what remains of his fear?". As is also well known, the claim that bodily changes are sufficient or even just necessary for emotion has been criticised several times, for different reasons, and many attempts have been made to disprove it empirically (for overviews see e.g. Frijda 1986; Cornelius 1996; Prinz 2004).

In this paper I will not be concerned with the question of whether experiencing bodily feelings is necessary and/or sufficient for experiencing emotion. How one goes about tackling this issue and answering the question depends very much on what one takes bodily feelings to be (e.g. are they limited to visceral sensations? Or do they include musculoskeletal sensations?). Also, as it will become clearer below, it depends very much on how one understands the phenomenon of "experience" or, better here, "self-awareness". In this paper I rather start from the assumption that, as embodied and situated living organisms, we experience our body in various ways, depending on the context. This is the case also when we feel emotions, and the specific question in which 
I am interested is: how do we experience our body in emotion experience? Or, in other words, how do bodily feelings enter emotion experience? In this paper I thus take a descriptive rather than a normative stance, in the sense that I am not interested in criteria for establishing when a bodily change does or does not feel like an emotion. I take it as uncontroversial (irrespective of one's stance towards the James-Lange hypothesis) that we often experience our body when feeling an emotion, and what I am interested in is providing a detailed characterization of this experience.

More specifically, the occasion for the discussion in this paper is a (much less discussed) remark by James in the same chapter of the Principles of Psychology. At some point he writes that, in emotion, "every one of the bodily changes, whatsoever be, is FELT, acutely or obscurely, the moment it occurs" (James 1890, p. 451, emphasis in original). This remark is not explicated or further elaborated in James's text; as I shall suggest, however, one way to interpret it is by drawing an initial distinction between bodily feelings that are in the foreground of emotion experience, and bodily feelings that are in the background (section II and III, respectively). In section IV I compare the proposed distinction with the one between reflective and pre-reflective bodily selfawareness as discussed in some recent philosophical phenomenological works. Finally, in section V I use the distinction between foreground and background bodily feelings to characterize the experience of being absorbed in an activity, in contrast to the view that in absorption the body is forgotten or inconspicuous.

\section{Foreground bodily feelings}

What about "acutely felt" bodily feelings? These seem to be the kind of feelings most 
philosophers and psychologists have in mind when they discuss the bodily features of affect: in many emotion experiences, one's body somehow "stands out" from the field of awareness and engrosses one's mind - as when I perceive my heart beating very fast after ducking a viper suddenly spotted in the middle of the hiking trail, or when I feel a knot in my throat as I am to report the death of a loved one, or when I sense my stomach contracting as I walk by a patch of vomit on the pavement. In all these cases, the body comes to the foreground of awareness, as I shall put it: it comes into relief, it makes itself apparent, it asserts its presence.

As the examples above illustrate, sometimes what comes to the foreground in emotion experience are localized bodily sensations. Other times, the bodily feelings in affect can be more diffuse, i.e. they may involve the whole body, or most of it. ${ }^{1}$ For example, I may feel energized and up-beat in my whole body upon receiving good news; when embarrassed I may feel a large part of my body getting warm; sometimes I feel apathetic, heavy and encaged. Diffuse foreground bodily feelings are often best characterized as experiences of action readiness (Frijda 1986) - i.e. awareness of action tendencies or urges to act, in which one's body is felt as wanting to move. ${ }^{2}$ In joy, I may run, jump and throw my hands up in the air-yet joy can involve merely a felt urge to run, jump and throw my arms up in the air, just as in anger I can merely feel like hitting the desk, and grabbing and shaking objects around me.

The diffuse character of foreground bodily feelings in emotion experience shows up also in how people speak-like when English speakers say that they feel "empty", "drained" or "buoyant", or when they say: "the speech stirred everyone's feelings", "I am all shook up", "he was slightly ruffled by what he heard" (Kövecses 2000, p. 80, emphasis in original). One can also "tremble", "shiver", and "quiver all over" with 
emotion (op. cit., p. 81). Also, interestingly some emotions are associated with specific whole-body metaphors. For example, angry people "blow up", "burst out", "blow their stack", "flip their lid" or "hit the ceiling", suggesting that anger feels like "hot fluid under pressure in the bodily container" (op. cit., pp. 148-9). ${ }^{3}$

These linguistic expressions and metaphors of emotion also reveal the dynamical and kinetic character of emotion experience. In this sense, research on language converges with and complements the phenomenological account developed by Sheets-Johnstone $(1999 ; 2009)$, according to whom there is a very close link between emotion experience and movement. ${ }^{4}$ Her claim is well illustrated by the fact that the visual arts (painting, sculpture, but also theatre and dance) draw heavily on representations of movement to evoke specific feelings. Many of these "kinetic portrayals" evoke subtle affective nuances that are not easily put into words, but whose specific quality is nevertheless directly grasped by the observer. In dance and theatre, the same movement, such as a head lift, can induce very different affective impressions depending on the speed at which it is executed (paintings and sculptures can also evoke movement, by representing e.g. humans and animals, but also objects, in specific actions and by exploiting light and texture). Arguably, these portrayals effectively evoke emotions because they enact bodily movements that are structurally analogous to those we often live through in our own body when we experience the portrayed emotions. Even music, it has been suggested, evokes emotion by reproducing the dynamical-kinetic character of specific emotion experiences (Gabrielsson \& Juslin 2003; Johnson 2007, chapter 11); a piece of music that feels "angry" (think heavy metal) arguably feels so because it mimics the kinaesthetic character of anger, with its sense of bodily upsurge and frantic impulse to shake and kick. 
Localized foreground bodily sensations in emotion experience are mostly interoceptive, whereas more diffuse feelings involve primarily kinaesthetic sensations or action urges. ${ }^{5}$ Yet in some cases one can have relatively distributed foreground visceral sensations, spanning for example the middle of the body from the throat to the lower abdomen (in my experience, sense of guilt can feel like this); in the case of felt temperature, the sensation can involve the whole body or most of it (as in some cases of embarrassment). On the other hand, relatively localized kinaesthetic sensations may come to the foreground in other situations, as in feeling the urge to clench one's fists and punch. To complicate the picture, not only kinaesthetic, but visceral sensations as well have their own dynamical-kinetic character. ${ }^{6}$ Think of the heart beating in fear, for example; or, in some experiences of disgust, the stomach or even throat can be felt as contracting and "pulling back", so to speak. Lastly, localised and diffuse bodily feelings are not mutually exclusive. Localized bodily sensations (either visceral or kinaesthetic) can take place in a context of specific whole-body feelings-e.g. I may feel the desire to throw my arms up in joy in a context of feeling up-beat and energized; or, in grief, I may sense a painful knot in my upper stomach in a context of a more diffuse feeling of "weighing down".

To recapitulate, in this section I have suggested that James's "acute" bodily feelings in emotion experience are best characterized as foreground bodily feelings in which the body "stands out" in the field of awareness, comes into relief and asserts its presence. In foreground bodily feelings the body is apparent, and I believe that it is this kind of phenomenon that most philosophers and psychologists have in mind when they discuss the nature of emotion experience and, specifically, its bodily character. Note that I have not aimed to identify bodily feelings that are necessary or even sufficient for 
emotion experience. Rather, my goal has been to draw attention to some of the ways in which the body is felt in the foreground when we experience emotion. In this sense, in this section I have pointed out that the body can enter the foreground of awareness as more or less localized, and in various experienced dimensions (as visceral and as proprioceptive-kinaesthetic sensations).

No doubt however the discussion so far will have raised the question of whether it is the case that bodily feelings are always in the foreground of emotion experience. After all, when I am scared of the free bulldog running behind me as I cycle, I am very much focused on the noises behind me, trying to gauge whether the dog is actually running towards me, or just beside me. As several emotion theorists emphasize in various ways, emotions are importantly directed towards objects and events in the world. I will address this issue in the next section. For now I will just note that this example does not undermine the point that bodily feelings are often in the foreground of emotion experience in the way described above. Yet as it will become clearer, foreground bodily feelings do not exhaust the ways in which one's body can be felt in emotion experience.

\section{Background bodily feelings}

I will interpret James's claim that the body is sometimes "obscurely felt" in emotion experience as meaning that in some cases bodily feelings can remain in the background. As I shall try to explain, in this case the body does not "stand out" and is not apparent, but it is still nevertheless felt, in the sense that it contributes to giving the emotion experience its specific quality, it contributes to the specific way the experience feels. 
Take for example the situation in which I am sitting in a delayed train proceeding very slowly, just before a flight. My attention is focused on particular objects - the time indicated by my watch, the speed of the train, the conductor's announcements - rather than my body, and yet the whole experience has a quality of urgency characterized by a sense of tightness and confinement; when I finally relax in my plane's seat, the tension that has built up in my neck and shoulders comes to the foreground. My suggestion here is that the quality of the anxious experience in the train comprised (partly at least) a background awareness of my (tense and constrained) body. Similar considerations apply to my fear for the bulldog running behind me as I cycle. The quality of the experience can be influenced, I want to suggest, by how my body is lived in the background. My attention is directed towards the dog, but I also sense my bodily vulnerability and agitation-I have a background, non-attended sense of my body as rigid and ready to be attacked. These background bodily experiences are part of my fear for the dog, they contribute to its particular feel.

In these examples, background bodily feelings are best characterized as that through which a situation in the world is experienced by the subject as possessing a specific affective quality (such as a quality of dangerousness, of dullness, threat, intimidation, pleasantness, excitement, and so on). To borrow a useful metaphor, if one way to characterize the subjectively lived body is as a transparent window out of which one looks at the world (see for example the discussion in Legrand 2005), my suggestion here is that background bodily feelings are like coloured window glasses: in emotion experience one may be mainly oriented towards the world, whilst experiencing it as affectively toned (coloured) depending on how one's body is felt in the background (depending on the colour of the glass); different emotions affect the body (colour the 
glass) in different ways, and the affective quality of the experienced world (the perceived colour of the world beyond the glass) changes accordingly.

The notion of a bodily background of experience is not new; different characterizations have been proposed in various contexts, some of which come closer than others to what I mean by background bodily feelings in emotion experience. Looking at some of them will help me clarify my proposal.

Among the scientists, Damasio (1994, pp. 149-50) distinguishes three varieties of feelings: feelings of basic universal emotions (such as joy, fear, anger, sadness, etc.; see Ekman 2003), subtle variations of those (such as ecstasy and euphoria, panic and shyness, etc.), and background feelings. A background feeling "is not the Verdi of grand emotion, nor the Stravinsky of intellectualized emotion but rather a minimalist in tone and beat, the feeling of life itself, the sense of being [...] [it] is our image of the body landscape when it is not shaken by emotion" (pp. 150-1). Background feelings are typically unattended, but they can easily be reported: "we are only subtly aware of a background feeling, but aware enough to be able to report instantly on its quality" (ibid.). As bodily, unattended, and nevertheless "subtly felt", Damasio's background feelings resemble my background bodily feelings. Unlike the latter, however, they are not felt specifically during emotion experiences, but rather between them ("[a] background feeling corresponds [...] to the body state prevailing between emotions"; ibid., emphasis in original); they contribute mainly to our sense of well- or ill-being, colouring our awareness when we are not in the grip of emotion. Whereas it is important to point to this kind of background bodily experience, it is also important to recognize that background bodily feelings can play a role in, specifically, emotion experiences as well. ${ }^{7}$ 
A different account of background bodily awareness is given by Leder (1990), who distinguishes various modes of "disappearance" of the body, namely various ways in which we do not pay attention to our body and our body is therefore "absent". At some point (p. 24) he discusses the example of a person who starts listening to music while driving. As her attention shifts to the music, the bodily movements she performs to drive disappear from her awareness: they are relegated to the background of a bodily "I can" from where they can reappear if needed. Leder's term for this mode of disappearance of the body is background disappearance. Note however that what I call background bodily feelings are not supposed to disappear in this way. In Leder's example the body, once disappeared, does not influence the experience of what is central in the subject's awareness at the moment (i.e., in the example, the music). Background bodily feelings, on the other hand, do contribute to the quality of one's current emotion experience.

Leder (1990, chapter 2) also talks of deep, recessive visceral processes that we never feel, and yet support our organism and its conscious life. This form of background is even further removed from the one I am trying to point out, because here the background cannot be brought to attention (although it may become felt in some cases of pain and illness); in other words, Leder's "recessive body" is not transparent in any sense, but rather entirely “invisible” (to borrow Legrand's 2007 term). Leder's discussion comes closest to my notion of background bodily feelings when it acknowledges that the absent body can be felt indirectly via a change in how the world is experienced. In hunger, for instance, Leder (1990, pp. 51-2) notes that the whole corporeal field can be affected and, importantly, "since my corporeal field is always in relation to a world, the visceral saturates my environment as well. [...] The world itself 
shifts with a shift of the visceral".

Yet another account of background bodily awareness is to be found in Gurwitsch $(1964 ; 1985)$. Gurwitsch maintains that "feelings of central adjustment as well as other bodily feelings may accompany mental activities and [...] some awareness or other of our corporeity is actually there at every moment of conscious life" $(1985, \mathrm{p}$. 28). He also comments that this pervasive bodily awareness can be particularly "dim and indistinct" (p. 31). Although he does not discuss emotion, his account thus seems to leave room for the possibility that a kind of dim and indistinct bodily awareness (akin to background bodily feelings) may characterize some emotion experiences.

Crucially, however, for Gurwitsch bodily awareness, even if pervasive, is always irrelevant to what is going on centrally or focally in the subject's attention. More precisely, Gurwitsch distinguishes three "domains" or "dimensions" of consciousness that are supposed to be simultaneous and unified within each conscious act:

First, the theme: that with which the subject is dealing, which at the given moment occupies the 'focus' of his attention, engrosses his mind, and upon which his mental activity concentrates. Secondly, the thematic field which we define as the totality of facts, co-present with the theme, which are experienced as having material relevancy or pertinence to the theme. In the third place, the margin comprises facts which are merely copresent with the theme, but have no material relevancy to it. ${ }^{8}$ (Gurwitsch 1964, pp. 55-6, emphasis in original)

For example, the sentence that I am writing right now is the theme, the thoughts and 
chains of inferences that are relevant to what I am writing now make up the thematic field, and the awareness of my legs stretched under the desk belong to the margin.

Now, Gurwitsch is very clear that he takes bodily awareness to be always in the margin (unless of course the body is itself the theme, as when I examine the wrinkles of my hand). As such, bodily awareness can be co-present with the theme (indeed, as we saw, it is pervasive), but it can never influence it. The theme is completely indifferent to, and disconnected from, the margin; the latter does not in any way concern the contents of the theme, and can only "interfere" with it by becoming itself thematic (Gurwitsch 1985, p. xliv).

As I want to characterize them, however, background bodily feelings in emotion experience are not marginal; they are not completely irrelevant or unrelated to what “engrosses one's mind" at a given time. Take again the example of my fear of the dog. If we apply Gurwitsch's tripartion (but note that he never discusses the case of emotion experience), the theme is the dog, or rather the noises it makes behind me; the thematic field comprises the thoughts that it may bite me, that I could bleed or fall from the bike, etc.; the margin is made up by an indefinite number of co-present yet unrelated conscious thoughts, perceptions, bodily feelings, etc., including the awareness of my body as rigid and ready to be attacked. The latter is thus contingent and irrelevant to the theme, i.e. it cannot influence its contents; at most, the body can enter the focus of attention and become itself thematic, thus interfering with the initial theme.

This account overlooks however that the theme, in the example, is not just the noises made by the dog, but the danger they signify for me. I am afraid and, in fear, what I am focusing on is the danger. In this sense, what engrosses my mind is not indifferent to how I feel my body in the background. Were I to feel my body as immune 
to dog-bites or as strong enough to kick the dog away if it attacked me (and assuming that I am not cino-phobic), my experience of the affective quality of the situation would be different. I might not experience it as dangerous anymore; or I might still experience it as dangerous, but with a very different sense of the coping capacities of my bodywhich, I want to suggest, would change the quality of my fear.

In sum, Gurwitsch acknowledges the existence of an unattended dimly felt and indistinct bodily awareness that resembles my background bodily feelings. Yet he relegates bodily awareness to a marginal background which, even if pervasive and always co-present with the theme, does not in any way affect the latter. Background bodily feelings, however, are not marginal in this sense. In being able to contribute to the affective quality of a situation, they can affect the theme.

Sartre's [1943] (1958) notion of ground (which was influenced by Gestalt psychology) comes closer to my background, even though Sartre does not discuss this notion in relation to the specific case of the body. For Sartre, acts of attention constitute specific perceptual objects as forms (Gestalten) that detach themselves from a ground. The ground however does not cease to be perceived; it is still laterally or peripherally attended, and as such it is part and parcel of the experienced world. See for example the passage in which Sartre is looking for his friend Pierre in a café (op. cit., pp. 9-11). Pierre is not there, and as Sartre scans the café looking for him, its various parts shift to the ground and become objects of a merely lateral attention. Yet this ground remains part and parcel of Sartre's experience of the situation, in particular of his experience of Pierre-as-absent. Similarly, I want to suggest, in emotion experience bodily feelings can shift to the ground or background, whilst remaining part and parcel of the subject's experience, contributing to the specific experience it is. 
With some caution, other examples from Sartre can help characterize background bodily feelings. As Sartre discusses in another passage of Being and Nothingness [1943] (1958, pp. 331-9), one experiences physical pain “implicitly" (p. 332, emphasis in original), by experiencing the world in an altered way. In Sartre's example, he is sitting late at night trying to finish reading a philosophy book, and:

at the very moment that I am reading my eyes hurt. Let us note first that this pain can be indicated by the world; i.e., by the book which I read. It is with more difficulty that the words are detached from the undifferentiated ground which they constitute; they may tremble, quiver; their meaning may be derived only with effort, the sentence which I have just read twice, three times may be given as "not understood,' as 'to be re-read.' (p. 132)

We can take this example as illustrating a background bodily pain which is not attended, but nevertheless influences the experience of the world. The caveat, however, is that Sartre's own conception of consciousness does not allow him to say that the body in this example experiences itself as painful (see discussions in Fell 1965; Wider 1997; Sveneaus 2009). Consciousness for Sartre is "vacuous" and becomes "something" only when attended by the other's regard (or by the subject looking at itself from the perspective of the other). Thus a painful consciousness cannot properly inhabit my body, and my body cannot in itself feel painful. My pain is either indicated by how the world is given to me (in which case my body is entirely "passed over"), or made known to me as an object by the other's regard. ${ }^{9}$

Likewise for Sartre's [1939] (1962) discussion of the emotions. Here Sartre at 
some point claims that "during emotion, it is the body which, directed by the consciousness, changes its relationship with the world so that the world should change its qualities" (p. 65). Specifically, the world acquires for the subject "magical qualities" of e.g. dangerousness, sadness, and so on. Importantly, for Sartre this takes place via a transformation of the whole body: the body, by undergoing physiological changes distinctive of specific emotions and by being guided by consciousness, leads to an experience of the world as having a specific affective quality. Again, on his own account of consciousness, Sartre cannot say that the body which is upset in emotion, and through which consciousness transforms the world, experiences itself as upset (see also Fell 1965, pp. 202-3). In emotion the body is used by consciousness to change the world; consciousness even degrades itself in this process, but the body never experiences itself.

In background bodily feelings, on the other hand, the world comes to be experienced as having specific affective qualities via a body that is in some sense feltnot explicitly, but in the background. We can keep Sartre's central idea that the affective quality of the world is experienced through the body, by specifying however that the latter is not merely directed and "passed over" by consciousness, but is and remains inhabited by it.

Ratcliffe's (2008) existential feelings are in many respects like background bodily feelings — even though they are meant to correspond to a broader and more "fundamental" (from an existential point of view) class than emotional feelings. Existential feelings are "background orientations through which experience as a whole is structured" (p. 2); they affect the way reality is experienced by the subject, and include e.g. feelings of the surreal, the unfamiliar, the uncanny, feelings of comfort, 
feeling at home, etc. Ratcliffe also calls them "feelings of being", feelings of how one finds oneself in the world. At the same time, existential feelings are bodily feelings through which things are experienced (p. 36). The feeling body in existential feelings is the medium through which one experiences and makes sense of the world; importantly however, it does not completely disappear from awareness. Rather, it remains felt as that which does the feeling (see e.g. p. 106). One way in which Ratcliffe illustrates this point is via the analysis of the experience of various psychiatric conditions. He shows that often these conditions involve an altered sense of reality that goes together with altered bodily feelings. The latter are not necessarily attended, but even so their altered nature contributes to alterations in one's sense of world-belongingness.

Finally, it is worth noting that some clinical practices also refer to a background of bodily awareness. Mindfulness Based Cognitive Therapy (MBCT), for example, makes use of various body-focused exercises (such as body scans, mindful breathing, mindful walking, etc.) to render subjects increasingly aware in their daily lives of bodily feelings that are usually unattended and in the background. One purpose of increasing bodily awareness is to enable subjects to become better at detecting the onset of unwanted and unwholesome emotion experiences, thus improving their capacity for self-regulation (see Williams et al. 2007).

In sum, in this section I have suggested that it is possible to identify a level of background bodily feelings that are not attended and not even apparent, but that are nevertheless felt, in the sense that they contribute to the specific quality of an emotion experience; in particular, they can shape or "colour" the affective quality of a situation by being that through which the world is experienced. I have tried to clarify this notion by comparing it with existing discussions of background bodily awareness, indicating 
analogies and differences.

\section{Comparison with reflective and pre-reflective bodily self-awareness}

I will now compare foreground and background bodily feelings with the distinction one finds in philosophical phenomenology between reflective and pre-reflective selfawareness, and specifically between reflective and pre-reflective bodily self-awareness. As Zahavi (2005) discusses in detail, most phenomenologists agree that one can be selfaware (i.e. aware of oneself) in a reflective, as well as non-reflective or pre-reflective way. ${ }^{10}$ In reflective self-awareness, one's self is reflected upon and thus objectified -as e.g. when one considers his or her own intentions or actions to assess whether they are appropriate to a certain situation. In pre-reflective self-awareness, one's self is experienced or lived through as the subject of awareness, without any process of reflection on itself. As Zahavi (2005) emphasizes, all my conscious experiences include a minimal form of pre-reflective self-awareness, in that they are all non-reflectively experienced as mine. In other words, all my conscious experiences are always and necessarily given to me in the first person, immediately and directly; for example, when I smell freshly baked bread, I need not stop and think in order to realize that it is $m y$ experience; rather, the experience has an immediate quality of "mineness" (Zahavi 2005, pp. 124-32).

One can be reflectively and pre-reflectively self-aware in many respects-e.g. of one's own memories, desires, intentions, etc. Specifically, when self-awareness refers to awareness of one's own body, it is called bodily self-awareness. I am reflectively aware of my bodily self when e.g. I try to gauge whether I have gained weight by pinching the 
fat on my stomach or by looking at the shape of my body in the mirror. Pre-reflective bodily self-awareness, on the other hand, involves directly and immediately living through one's own body, as when I am immersed in a specific activity (such as writing this paper) and my attention is thus not on my bodily self. In this case my body is however not completely invisible or absent from my experience either. In fact, I am (pre-reflectively) aware that I am writing through my typing hands, for example; or that I occupy a specific position in relation to the computer screen, etc. As Legrand (2007) summarizes it, reflective bodily self-awareness is a thematic, observational consciousness of one's own body as an object, whereas pre-reflective bodily selfawareness is an unmediated, nonthematic way of being aware of one's bodily self as the subject of one's experiences. ${ }^{11}$

How does this distinction map onto the one between foreground and background bodily feelings drawn above? Prima facie, background bodily feelings would appear to be pre-reflective (they are clearly unheeded and unattended), whereas foreground bodily feelings would appear to be reflective. Pre-reflective self-awareness is often characterized as a hidden, marginal, almost non-conscious level of consciousness; correlatively, any experience that is not marginal but rather "at the front", self-affirming and mind-engrossing tends to be characterized as thematic and reflective. Petitmengin (2007, p. 55), for example, writes: "we use the term 'pre-reflective' in order to emphasize the fact that this dimension is not unconscious, but only not yet conscious". She is particularly interested in developing methods (such as interviews) that enable people to become aware of a variety of pre-reflective material. The latter is assumed to be hidden, at the fringe, non-conscious, and the subject needs the help of a second person to turn attention to this material and thereby to become aware of it. 
Or, consider again Leder's (1990) reflections on the absent body, this time his account of pain. In his example, a tennis player is entirely absorbed in the game when he suddenly feels an acute pain in his chest. Prior to the onset of the pain, his body is absent, not attended (in various ways); as the pain suddenly appears, the tennis player refocuses his attention on the state of his body. As Leder puts it: "[a] background region, the chest, is now thematized" (p. 71); and "[t]he sensory insistence of pain draws the corporeal out of self-concealment, rendering it thematic" (p. 76). Moreover, for Leder pain is alienating: the painful bodily parts appear in the specific mode of $d y s-$ appearance, i.e. they appear as dysfunctional. In his example we thus have, on the one hand, a pre-reflective bodily background (the tennis-playing body) which, as such, is unheeded; on the other hand, we have a clearly noted localized bodily sensation (the pain in the chest) which, as such, is thematic and reflective.

Finally, take Lambie \& Marcel's (2002) account of, specifically, localized bodily sensations in emotion experience. The authors distinguish between what they call firstorder phenomenal experience and second-order awareness. In their view, awareness of individual bodily parts in emotion experience is brought about by a reflective state of second-order awareness, i.e. an explicit act of observation of one's first-order experience. $^{12}$

I agree that background bodily feelings are, indeed, best characterized as prereflective. They are not attended, they are not reflected upon; they are experienced, although only insofar as they contribute to the specific feel of an emotion experience. What about foreground bodily feelings however? Importantly, as I want to characterize it, the foreground is not attended as an object — it is not observed or reified in any way. In foreground bodily feelings, my body is clearly subjectively lived. It comes to the 
front of awareness, it can even be overwhelming in its physical presence, but it does so in a non-mediated and non-reflective way. To borrow Lambie \& Marcel's (2002) own terminology (but not their view), foreground bodily feelings are instances of first-order phenomenal awareness; they need not be attended by second-order awareness in order to be experienced.

This view of course does not exclude that I can take an attentive and reflective stance towards my bodily feelings and examine their object-like features: while crying in sadness, I may consider the saltiness of my tears; when anxious, I may put a hand on my chest to gauge the speed of my heartbeat. How this mode of attention influences my emotion experience is an interesting empirical question with important therapeutic implications. I may even willingly cultivate an observational stance towards my bodily feelings (as in MBCT), to learn to catch myself in the grip of some emotional outburst, and eventually to regulate my emotions. Also, sometimes the coming to the foreground of bodily feelings may be what leads the subject to take a reflective stance toward them. Indeed, this may be why, in some cases of pain and illness, the body may come to be experienced as alien (Leder 1990; Svenaeus 2009): when the pain becomes the object of attention, it becomes to some extent reified and therefore experienced as other than $m y$ pain. Something similar may happen in emotion experience.

As I want to characterize them, then, both foreground and background bodily feelings in emotion experience can be pre-reflective, non-objectifying modes of awareness of one's own body. As for the difference in how they feel, we can say that they differ in degree of self-presentation or self-intimation: "experiential states do present themselves, but not as objects. Metaphorically speaking, experiential states are characterized by a certain self-luminosity; they are self-intimating or self-presenting" 
(Zahavi 2005, p. 61). The thought here is that both background and foreground bodily feelings are non-objectifying modes of living through one's own body in emotion experience; the former, however, are somehow "less present" to oneself than the latter (or, continuing the metaphor of self-luminosity, they are somehow "dimmer" than the latter). In still other words, background and foreground bodily feelings do not differ in kind, in the sense that they are both pre-reflective; they differ however in degree, with the former being more recessive than the latter.

That there can be different forms of pre-reflective bodily self-awareness which vary in degree of self-presentation is discussed by Legrand (2007) and substantiated by her distinction between the performative and the transparent body. As she characterizes it, the performative body is the body as experienced during the skilful performance of a specific activity, ${ }^{13}$ and is well illustrated with the case of expert dancers: the expert dancer need not reflect on her body to control her moves, but neither is her body entirely out of awareness and out of control; rather, in a dancer's own words, the expert dancer "moves from a sharp and very present physical state" (Hermans 2003, quoted in Legrand 2007, p. 501). Legrand (p. 505) notes that this is a case in which bodily experience is pre-reflective and nevertheless " at the front"”. 14 The transparent body, on the other hand, is a bodily experience of the world. The body here is pre-reflective in the sense that it is experienced as that through which one looks at the world. We normally primarily attend to events in our surroundings, namely we are projected or oriented towards the world rather than our body. Yet this world-orientation comes with a sense of bodily presence, of orientation and agency; the latter are not objectifying perceptions of one's own body, but pre-reflective modes of self-awareness constitutive of one's experience of the world. As Legrand summarizes it, "dancers mostly experience their 
body pre-reflectively, whereas normal people in normal circumstances mostly experience the world in a bodily way" (p. 506, italics in original). Both are nonreflective forms of bodily subjectivity, but the transparent body is, as I want to put it, more recessive, more in the background.

Characterizing both background and foreground bodily feelings as instances of pre-reflective bodily self-awareness allows to eschew a possible criticism. Both Zahavi (2005) and Legrand (2007) warn against conceptualizing pre-reflective bodily selfawareness as "marginal” or "peripheral" awareness of one's own body. Specifically, Zahavi (p. 63) criticizes the suggestion "that our pre-reflective experience remains in the background as potential themes - in precisely the same way as does, say, the hum of the refrigerator" because, he remarks, this suggestion ultimately

remains stuck in the subject-object model. It remains committed to the idea that our experiential life must either be given as an object or not be given at all and lets the only allowed variable be whether the object is given thematically or only marginally. This line of thought is flawed, however, since it erroneously assumes that there is only one type of givenness or manifestation, that of object-givenness. (ibid.)

Likewise, Legrand (2007, p. 512) writes: "attending to something that would have been peripheral, thus making it central, would only allow the focus on the self-as-object, and not on the self-as-subject". This caveat, however, does not apply to my discussion, because even though the background may be seen, in some sense, as "marginal" or "peripheral" when compared to the foreground, the body is not given as an object in 
foreground bodily feelings. When background feelings come to the foreground (as when I feel again the headache I had forgotten during the meeting), they do not lose their character of pre-reflectivity. Of course, I may also take the further reflective step and notice "oh, my headache is back, it is really quite bad now", but this step is not necessary for the headache to come to the foreground. The pre-reflective, as we saw, can be more or less self-presenting, and can come more or less to the front. ${ }^{15}$

In sum, the distinction between foreground and background bodily feelings does not map onto the one between reflective and pre-reflective bodily self-awareness; foreground and background bodily feelings are both forms of pre-reflective bodily selfawareness in which the body is subjectively lived through, and which differ in degree of self-intimation or self-presentation.

\section{The case of absorption}

I will now use the distinction between foreground and background bodily feelings to characterize the experience of being absorbed in an activity in a way that, as I shall argue, does more justice to its phenomenology than existing accounts.

The tendency to view the pre-reflective body as hidden and non-conscious goes together with the tendency to view absorption in an activity as primarily world-oriented and, correlatively, as involving an inconspicuous body. Take Leder's (1990) tennis player again: before suddenly feeling a pain in the chest, the tennis player is totally absorbed in the game and his body is absent, or more precisely ecstatic - it is projected outward towards the world and away from itself (pp. 18, 21-2). The other face of this view is that noticing one's own body will lead to disrupting the state of absorption. In 
Polanyi's words: "if a pianist shifts his attention from the piece he is playing to the observation of what he is doing with his fingers while playing it, he gets confused and may have to stop" (Polanyi 1958, p. 56, quoted in Leder 1999, p. 85). Ratcliffe (2008) also at some point observes that often, when one's body becomes "conspicuous", one's experience of the world looses fluidity and becomes impeded: "the conspicuous body is [...] often a retreat from a significant project in which one was previously immersed, a loss of practical possibilities that the world previously offered" (p. 125). He gives the example of realizing, while giving a lecture, that one's audience is getting bored ( $\mathrm{p}$. 114). Before this realization, the body is inconspicuous and the lecture proceeds smoothly; as soon as the realization dawns, the body becomes gradually more conspicuous, and the fluidity of one's gestures and speech breaks down.

It is certainly the case that taking a reflective stance towards one's body while being absorbed in an activity can disrupt one's absorption and performance, by transforming one's subjectively lived body into an object of perception. But how are we to understand the experience of absorption itself? Does it really involve an inconspicuous and forgotten body? I think that this account is inappropriate, and that absorption is better characterized as involving alternations of (pre-reflective) background and foreground bodily feelings, namely different degrees of selfpresentation or self-intimation of the lived body.

Let us take a closer look at the example of being absorbed in playing the piano. In my experience, this state does not go together with an inconspicuous body. Throughout the activity, my bodily posture, my facial expressions, and/or the way my fingers touch the keys come to the foreground; I feel my body resonating with the music, with momentary surges of physical tension, perceived in my viscera as well as muscles, and 
entangled with the affective quality of the music. These bodily feelings are not disruptive; on the contrary, they are part and parcel of the excitement, as well as of the enjoyment of the situation. They do not disturb the overall experience, but rather enrich it by adding texture to it. Now, it may happen that, while playing, I become reflectively aware of my facial expressions, and feel embarrassed about them (especially if playing in front of other people); absorption is then disrupted and I am more likely to make mistakes. But this is only one way in which my body can become "conspicuous". The body can become conspicuous without being objectified, by being pre-reflectively experienced in the foreground.

Sudnow's (1978) first-person account of his experience of learning how to improvise jazz on the piano supports this description. It is clear from his report that at the beginning of his training he took a reflective observational stance towards his hands and technique. For example, he knew that "higher" and "lower" passages should alternate in relatively quick succession, and put this knowledge into practice by reflectively moving and controlling his hands; he also looked at his hands and fingers most of the time. As he improved, however, he shifted to a more embodied and nonreflective knowing how, and began to be guided more by touch and proprioceptive sensations: "[1] ooking workload progressively lightens [...] As I reached for chords [...] I was gaining a sense of their location by going to them, experiencing a rate of movement and distance required at varying tempos, and developing, thereby, an embodied way of accomplishing distances" (p. 12).

This more "embodied way" of playing does not lead Sudnow to, eventually, forget his body, and is clearly never aimed at achieving an automatic performance deprived of bodily presence. Rather, Sudnow's report indicates that, with practice, he 
learns to "submit" to the increasing skills of his hands (interestingly, in the narrative "the hand" gradually replaces the "I" as the improvising agent) and eventually learns to "sing with his fingers" - as he often likes to put it in the book. This expression aptly evokes a state of immersion in one's body in which the body is however still experienced as a source of feeling, affect, agency, and expressivity. Sudnow's account also shows a progressive expansion of bodily self-awareness, from the hands to the rest of the body. Here is a passage from the final part of the book which describes his experience as a now accomplished jazz improviser:

The articulational course could now take up in downbeat synchrony with the foot; now in upbeat synchrony with the left hand's rise toward a next chord; now in top-of-the-turnaround synchrony within the one-shoulder-sway-per-four-foot bounces; now jumping in on the upbeat phase of a chordal reaching arc and taking a soundful traverse through thus and so many places to a foot downbeat, one that was 'located within' the course of the broader reaching arc of the chordal stretch. (Sudnow 1978, p. 140)

Not only the fingers, but the whole body is here experienced as involved in the performance. Even if this description is post hoc and thus necessarily reflective, it is hard to imagine that it could have been produced in the absence of any form of bodily conspicuousness. It is more plausible to grant that Sudnow is here tapping a dimension of pre-reflective bodily self-awareness that clearly reveals not a forgetting of the body but rather a dynamics of foreground and background bodily feelings, in which some parts of the body stand out and others shift to the background. 
Csikszentmihaly (1992), in his popular book on happiness, discusses many reallife instances of what he calls the experience of flow, "the state in which people are so involved in an activity that nothing else seems to matter" (p. 5). One context in which flow-experiences come about, he argues, is when people perceive their body skilfully performing a specific activity, such as playing an instrument, dancing, hiking, climbing, practicing Yoga and martial arts, etc. (see chapter 5, titled "the body in flow"). Csikszentmihaly is primarily interested in identifying the various activities in which people experience "the body in flow", and does not really provide a detailed characterization of what it is like to be in this state. What he says, however, is inconsistent with the view that during bodily flow the body is forgotten or inconspicuous - or so I want to suggest. On the one hand, Csikszentmihaly insists that a high level of expertise is required to experience bodily flow; expertise is necessary for the activity to proceed smoothly, without breakdowns and frustrations. Yet on the other hand he also repeatedly emphasizes the importance of feeling challenged during the activity, as well as feeling that one can cope with the challenge. The experience of bodily flow, then, must involve a delicate equilibrium of mastery and effort, such that the experience of being challenged and the experience of dealing with the challenge unfold seamlessly, in a state of uninterrupted absorption. How could such an equilibrium be achieved and experienced without some form of bodily conspicuousness? One ought to be able to feel one's body as it is being challenged, and to feel when the challenge is being overcome. During bodily flow, I maintain, one does not forget one's body but rather one lives it through, pre-reflectively, as actively immersed in a demanding but not overpowering pursuit; this condition involves a dynamical interplay of foreground and background bodily feelings, namely different 
degrees of self-presentation of the body.

Similar considerations apply to a variety of sensual experiences, most obviously erotic experiences, but also e.g. listening to music, enjoying a walk, exercising. They do not apply to pleasant experiences only however. As I am calling a relative to communicate the death of a loved one, I am trying not to cry, but every now and then a knot in my throat comes to the foreground; I push it in the background, from which it keeps shaping my experience, giving it a character of tightness and effort. Or, I may be absorbed in a boring activity, like entering dozens and dozens of marks into the dedicated form; it is drizzling outside and the whole experience is suffused with sleepiness, my face feels long, my jaws lazy and my eyelids heavy. These bodily feelings come to the foreground every now and then, and otherwise stay in the background, giving the experience of boredom its character of heaviness and slowness.

In sum, the notions of foreground and background bodily feelings can be used to characterize the experience of being absorbed in an activity not merely as a case of bodily forgetfulness and inconspicuousness, but as a richer or better thicker experience in which one's body can be felt "at the back" as well as "at the front" of awareness, without thereby losing its character of subjectively lived body.

\section{Conclusion}

I have taken the claim that emotion experience involves bodily feelings not as an end point, namely a hypothesis to be confirmed or rejected, but as a starting one - that is, as an uncontroversial statement about the phenomenology of emotion which nevertheless still needs to be further elaborated and analysed. James's remark that the body is 
"FELT, acutely or obscurely" when we feel an emotion has served as the occasion for developing an account of "foreground" and "background" bodily self-awareness in emotion experience. The characterization of the latter, in particular, has led to considering other existing notions of background awareness of one's body. Whereas various such notions are available, the one of background bodily feelings proposed here applies specifically to the case of how the body can be felt in emotion experience, and as such it does not appear to reduce to existing characterizations of background bodily experiences - even though, as shown, it does come closer to some than others.

The subsequent comparison of the distinction between foreground and background bodily feelings on the one hand, with the one between reflective and prereflective bodily self-awareness as drawn in recent philosophical phenomenological works one the other, has helped further characterize the place of the body in emotion experience. I have concluded that both foreground and background bodily feelings should be considered experiences of one's own body that do not objectify it. They are thus best characterized as different forms of pre-reflective bodily self-awareness, in which one's own body is more or less recessive or self-presenting.

Thus understood, the distinction between background and foreground bodily feelings has enabled a more appropriate account of the experience of being absorbed in an activity. I have argued that even if in absorption one's attention is primarily worldoriented, one's body is not inconspicuous but rather involves bodily experiences that move "back and forth" in awareness, so to speak, without being thematized and objectified. Such an account, I believe, ultimately allows us better to appreciate the thoroughly bodily character of absorption. 


\section{Acknowledgements}

This work is funded by the European Research Council under the European Community's Seventh Framework Programme (FP7/2007-2013), ERC grant agreement nr. 240891. I am particularly grateful to Dorothée Legrand for her suggestions on a previous draft and her patience. I also thank the referees and editorial board of Inquiry for their advice; thanks also to the audience of the Bodily Phenomenology conference organized by Fredrik Svenaeus and Martin Gunnarson at Södertörn University in May 2010

\section{References}

Armstrong, D.M. (1962) Bodily Sensations (London: Routledge \& Kegan Paul).

Cornelius, R.R. (1996) The Science of Emotion: Research and Tradition in the Psychology of Emotion (Upper Saddle River, NJ: Prentice Hall).

Craig, A.D. (2003) "Interoception: The sense of the physiological condition of the body", Current Opinion in Neurobiology, 13, pp. 500-5.

Csikszentmihaly, M. (1992) Flow: The Psychology of Happiness (London: Rider).

Damasio, A.R. (1994) Descartes' Error: Emotion, Reason and the Human Brain (New York: Putnam) 
Ekman, P. (2003) Emotions Revealed: Understanding Faces and Feelings (London: Weidenfeld \& Nicholson).

Fell, J.P. III (1965) Emotion in the Thought of Sartre (New York: Columbia University Press).

Frijda, N.H. (1986) The Emotions (Cambridge: Cambridge University Press).

Gabrielsson, A. \& Juslin, P.N. (2003) “Emotional expression in music”, in: R.J.

Davidson, K.R. Scherer \& H.H. Goldsmith (Eds), Handbook of Affective Sciences, pp. 503-34 (Oxford: Oxford University Press).

Gallagher, S. (2005) How the Body Shapes the Mind (Oxford: Oxford University Press).

Gurwitsch, A. (1985) Marginal Consciousness (Athens, OH: Ohio University Press).

Gurwitsch, A. (1964) The Field of Consciousness (Pittsburgh: Duquesne University Press).

Hermans, C. (2003) "When the body takes over", http://www.du.ahk.nl/mijnsite/papers/impro.htm

James, W. (1890) Principles of Psychology (New York: Holt). 
Johnson, M. (2007) The Meaning of the Body: Aesthetics of Human Understanding (Chicago \& London: The University of Chicago Press).

Kövecses, Z. (2000) Metaphor and Emotion: Culture, Language, and Body in Human Feeling (Cambridge: Cambridge University Press).

Lambie, J.A. \& Marcel, A.J. (2002) "Consciousness and the varieties of emotion experience: A theoretical framework", Psychological Review, 109, pp. 219-59.

Lange, C.G. (1885) “The emotions: A psychophysiological study”, in: C.G. Lange \& W. James (1922) The Emotions, pp. 33-90 (Baltimore: Williams and Wilkins).

Leder, D. (1998) The Absent Body (Chicago \& London: The University of Chicago Press).

Legrand, D. (2007) "Pre-reflective self-consciousness: On being bodily in the world", Janus Head, 9, pp. 493-519.

Legrand, D. (2005) “Transparently oneself. A commentary on Metzinger, Being No One", Psyche, 11 (5). http://psyche.cs.monash.edu.au/symposia/metzinger/LEGRAND.pdf

Montero, B. (2010) “Does bodily awareness interfere with highly skilled movement?", 
Inquiry, 53, pp. 105-22.

Petitmengin, C. (2007) "Towards the source of thought: The gestural and transmodal dimension of lived experience", Journal of Consciousness Studies, 14, pp. 54-82.

Polanyi, M. (1958) Personal Knowledge: Towards a Post-critical Philosophy (Chicago \& London: The University of Chicago Press).

Prinz, J.J. (2004) Gut Reactions: A Perceptual Theory of Emotion (Oxford: Oxford University Press).

Ratcliffe, M. (2008) Feelings of Being: Phenomenology, Psychiatry and the Sense of Reality (Oxford: Oxford University Press).

Ryle, G. (1951) "Feelings”, The Philosophical Quarterly, 1, pp. 193-205.

Ryle, G. (1949) The Concept of Mind (New York: Barnes \& Noble Books).

Sartre, J-P. [1943] (1958) Being and Nothingness: An Essay on Phenomenological Ontology, trans. Barnes, H.E. (London: Methuen).

Sartre, J-P. [1939] (1962) Sketch for a Theory of the Emotions, trans. Mairet, P. (London: Methuen). 
Scheler, M. [1913, 1916] (1973) Formalism in Ethics and Non-Formal Ethics of Values, trans. Frings, M.S. \& Funk, R.L. (Evanston: Northwestern University Press).

Sheets-Johnstone, M. (2009) “Animation: The fundamental, essential, and properly descriptive concept", Continental Philosophy Review, 42, pp. 375-400.

Sheets-Johnstone, M. (1999) "Emotion and movement: A beginning empiricalphenomenological analysis of their relationship", Journal of Consciousness Studies, 6, pp. 259-77.

Sudnow, D. (1978) Ways of the Hand: The Organization of Improvised Conduct (London: Routledge).

Svenaeus, F. (2009) “The phenomenology of falling ill: An explication, critique and improvement of Sartre's theory of embodiment and alienation”, Human Studies, 32, pp. 53-66.

Wider, K.V. (1997) The Bodily Nature of Consciousness: Sartre and Contemporary Philosophy of Mind (Ithaca: Cornell University Press).

Williams, M., Teasdale, J., Segal, Z. \& Kabat-Zinn, J. (2007) The Mindful Way through Depression: Freeing Yourself from Chronic Unhappiness (New York: The Guildford Press). 
Zahavi, D. (2005) Subjectivity and Selfhood: Investigating the First-Person Perspective (Cambridge MA: MIT Press). 


\section{ENDNOTES}

${ }^{1}$ Others have distinguished between localized bodily sensations and more diffuse or non-localized bodily feelings (e.g. Ryle 1949, 1951; Armstrong 1962; Scheler [1913, 1916] 1973), although not always specifically in the context of describing emotion experience. Armstrong (1962), for example, does not address the case of emotion and limits his discussion to localized bodily sensations such as itches, pains, sensations of pressure, etc.

${ }^{2}$ Awareness of action readiness is thus not a mere intention to act, as in intending to switch on the computer or intending to go swimming; an intention to act may occur without any bodily feeling or, for that matter, without any feeling at all.

${ }^{3}$ Of course not only English speakers have bodily expressions and metaphors for emotion experience. Kövecses (2000) discusses analogies with Hungarian and many other languages.

${ }^{4}$ For Sheets-Johnstone emotion experience is actually inherently kinaesthetic, i.e. it necessarily involves experience of bodily movement, or at least of possibilities for bodily movement; on the other hand, each bodily movement always has its own distinctive affective character. As she puts it, emotion experience and movement are “experientially intertwined” (1999, p. 264) and “mutually congruent” (1999, p. 265). We can leave the constitutive claim aside here, and just note that, indeed, we often experience kinaesthetic sensations in emotion, and we often perceive movement as affectively laden.

${ }^{5}$ A reminder that in physiology, interoception refers to the perception of internal states of the body, as it occurs e.g. in pain, perception of bodily temperature, itch, visceral sensations (e.g. gut movements), vasomotor activity, hunger and thirst. Proprioception 
refers to the perception of the size and location of one's body and limbs; kinaesthesia, which refers specifically to perception of movement of one's body, is part of proprioception. The interoceptive system appears to be anatomically distinct from the proprioceptive one; the former is associated with autonomic motor control, whereas the latter is part of the exteroceptive system (Craig 2003).

${ }^{6}$ Sheets-Johnstone focuses on the dynamics of kinaesthetic sensations only, and does not discuss interoception (see Sheets-Johnstone 1999; 2009).

${ }^{7}$ Emotion experience in Damasio is always the feeling or "image" of one's body undergoing some changes (as in James). There is thus no room in his account for what I mean by background bodily feelings in emotion experience: for Damasio, either there is an emotion experience in which the body is the explicit object of one's awareness, or there are background feelings, but only between emotion experiences.

${ }^{8}$ Gurwitsch (1964) presents his distinction as an elaboration and refinement of James's (1890, chapter 9) notion of fringes. Broadly speaking, the latter correspond to Gurwitsch's thematic field; they are a dimly felt domain of relevancy or affinity. ${ }^{9}$ This is a matter of debate and interpretation, but see the following remarks: "What then is this pain? Simply the translucent matter of consciousness, its being there, its attachment to the world, in short the peculiar contingency of the act of reading. [...] pain as a contingent attachment to the world can be existed non-thetically by consciousness only if it is surpassed. Pain-consciousness is an internal negation of the world; but at the same time it exists its pain—i.e., itself — as a wrenching away from self. Pure pain as the simple 'lived' cannot be reached" (Sartre [1943] 1958, p. 333). ${ }^{10}$ As he points out, Sartre is perhaps the best-known defender of a phenomenological theory of self-awareness, but relevant discussions can also be found in Husserl, 
Heidegger, and many others. Also, Zahavi usefully reminds us that Sartre initially used the terms "irreflective" or "nonreflective" self-awareness, and only later came to prefer "pre-reflective".

${ }^{11}$ This distinction is sometimes also put in terms of the difference, especially emphasized by Husserl, between one's Körper and one's Leib. Both German terms translate into English as "body", but Körper refers to the body as a physical (spatiotemporal) object, whereas Leib refers to the body as lived through from the perspective of the subject (see Zahavi 2005, p. 206). Note however that someone else's Leib can be the object of my reflective awareness (I may notice someone's compassionate smile, for example).

${ }^{12}$ In their words: "The bodily changes are not available in experience as separate components (e.g., as heartbeat, temperature, tenseness) unless analytically attended in second-order awareness" (Lambie \& Marcel 2002, p. 238); “[s]ome theorists might view conscious experience of bodily states, such as body temperature, muscular tension, abdominal sensation, lump in throat, tears welling up, as first-order emotion experiences. We see these experiences, however, as part of second-order emotion experience. They are the result of analytic attention to aspects of the bodily self" ( $o p$. cit., p. 239). "Analytic" here refers to one possible mode in which, according to the authors, attention can turn to first-order awareness (it is opposed to the "synthetic" mode).

${ }^{13}$ See also Gallagher $(2005$, pp. 74,91$)$ for the notion of "performative awareness". ${ }^{14}$ Montero (2010, p. 113) similarly reports her conversation with a professional dancer who explains that, when she performs, she aims "to be totally immersed in the feeling of [her] body moving". 
${ }^{15}$ As Legrand (2007, p. 512) herself puts it, "the self-as-subject (or the subjective character of experience) is not necessarily peripheral, or marginal. Expertise (with one's body as in dance, or with one's mind as in some meditative states) can overcome this "self-forgetfulness" (as Husserl would put it) and put this subjective character of experience "at the front" of one's experience without turning it into a mere intentional object". 